\title{
Synthesis of New 5-Trifluoromethyl-3-alkyl[aryl(heteroaryl)]-4- (2-benzyl-3-hydroxycyclohex-2-enone-2-yl)-1H-pyrazoles by a Ring-Opening Reaction
}

\author{
Jussara Navarini (PG), Helio G. Bonacorso* (PQ), Carson W. Wiethan (PG), Rosália \\ Andrighetto (PG), Fábio M. Luz (IC), Marcos A. P. Martins (PQ), Nilo Zanatta (PQ)
}

Núcleo de Química de Heterociclos (NUQUIMHE), Departamento de Química, Universidade Federal de Santa Maria, 97105-900, Santa Maria, RS. *E-mail heliogb@base.ufsm.br

Keywords: Fluorine-containing, Hidrazine, Pyrazoles

\section{INTRODUCTION}

Pyrazoles, including those containing fluorine, are a well-studied class of organic compounds that have found diverse uses in technology, medicine and agriculture. ${ }^{1}$ Many pyrazole derivatives are known to exhibit a wide range of biological activity, of which can highlight arylpyrazoles, as Celecoxib, a cyclooxygenase-2 inhibitor. ${ }^{2,3}$

On the other hand, chromenones are important compounds with biological activity, as well components of natural products. Moreover, they can be use as valuable substrates for the synthesis of pharmacologically interesting compounds. ${ }^{4}$ For instance, reaction of chromenones with 1,2nucleophilic reagents, such as hydrazines would lead to the possible competition involving three different electrophlilic centers (acyl group at C-3, C-5 and $\mathrm{C}-8 \mathrm{a}$ ). In the present study, we wish to report the results of the reactions of 2-hydroxy-2Hchromenones ${ }^{5}$ with hydrazine.

\section{RESULTS AND DISCUSSION}

The reactions of chromenones 1 with hydrazine monohydrate (1:2) were performed under reflux of ethanol for 16 hours leading to the 5-trifluoromethyl3-alkyl[aryl(heteroaryl)]-4-(2-benzyl-3-hydroxycyclohex-2-enone-2-yl)-1 $\mathrm{H}$-pyrazoles (2) as oil, in 68-80 $\%$ yields (Scheme 1). Subsequently, as an example of compounds 2 ( $\left.\mathrm{Ar}=\mathrm{Ph}, \mathrm{R}^{1}=\mathrm{CH}_{3}\right)$, a $\mathrm{N}$-alkylation reaction was performed using benzyl chloride as alkylating agent, in the presence of sodium hydride in DMF at room temperature for 24 hours. Compound $\mathbf{3}$ was obtained as oil in $70 \%$ yield. All structures synthesized were characterized by NMR $\left({ }^{1} \mathrm{H}\right.$ and $\left.{ }^{13} \mathrm{C}\right)$ spectroscopy and GC/MS.

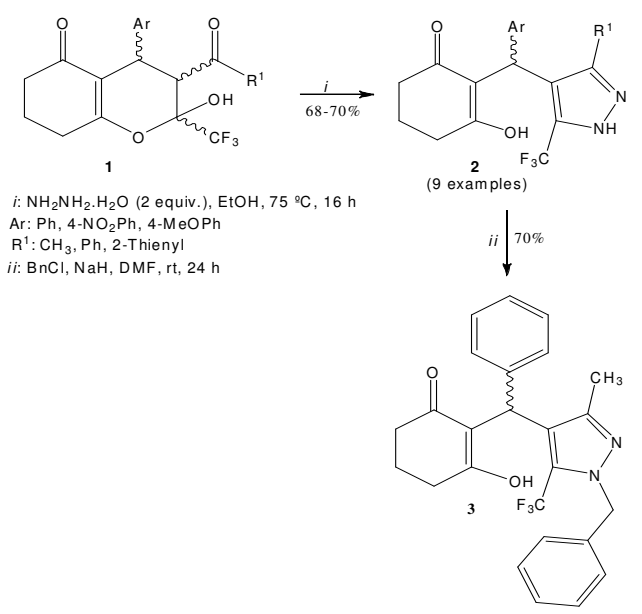

Sheme 1. Synthesis of new pyrazoles

\section{CONCLUSION}

In this work, the employed methodology proved to be a simple and efficient way to obtain exclusively and regioselectively new pyrazoles, despite the three distinct electrophlilic centers present in the trifluoromethylated chromenones precursor.

\section{ACKNOWLEDGEMENTS}

\section{CNPq-CAPES-FATEC}

\section{REFERENCES}

1 Sonovskikh, V. Ya. Barabanov, M. A.; Sizov, A. Yu. Russ. Chem. Bull., Int. Ed. 2002, 51, 1290.

Ranatunge, R. R.; Earl, R. A.; Garvey, D. S.; Janero, D. R.; Letts, L. G.; Martino, A. M.; Murty, M. G. ; Richardson, S. K.; Schwalb, D. J.; Young, D. V.; Zemtseva, I. S. Bioorg. Med. Chem. Lett. 2004, 14, 6049.

${ }^{3}$ Xia, Y.; Dong, Z.; Zhao, B.; Ge, X.; Meng, N.; Shin, D.; Miao, J. Bioorg. Med. Chem. Lett. 2007, 15, 6893.

${ }^{4}$ Rueping, M.; Sugiono, E.; Merino, E. Chem. Eur. J. 2008, 14, 632.

${ }^{5}$ Bonacorso, H. G.; Navarini, J.; Wiethan, C. W.; Bortolotto, G. P.

Paim, G.R.; Cavinatto, S.; Martins, M. A.; Zanatta, N.; Caro, M. S.

B. J. Fluorine Chem. 2011, 132, 166. 